\title{
Rapid Qualitative Compositional Analysis of Ceramic Paints
}

\author{
Jeffrey R. Ferguson ${ }^{\mathrm{a}}$, Scott Van Keuren ${ }^{\mathrm{b}}$, and Shilo Bender ${ }^{\mathrm{a}}$
}

$4 \quad{ }^{a}$ MURR Archaeometry Laboratory, University of Missouri, Columbia, MO 65211, USA

5 (Ferguson is the corresponding author; 573-882-5241, fergusonje@ missouri.edu)

6

7

${ }^{\mathrm{b}}$ Department of Anthropology, University of Vermont, Burlington, VT 05405, USA 
11 Abstract

12 In previous research Van Keuren and colleagues used time of flight-laser ablation-inductively coupled plasma-mass spectrometry (TOF-LA-ICP-MS) to infer distinct paint composition groups in glaze-painted White Mountain Red Ware (WMRW) from late pre-Hispanic villages in eastern Arizona. This analytical approach cannot be reasonably applied (in a non-destructive way) to the study of paint composition on whole vessel collections. To expand the earlier study and examine the link between compositional group and whole vessel decoration, we used portable $\mathrm{x}$-ray fluorescence (pXRF) to qualitatively examine the composition of glaze-painted designs on a large corpus of WMRW whole vessels curated at the National Museum of Natural History. This paper summarizes the previous ICP research, explains the methodology behind the qualitative XRF analysis, presents the results of the whole vessel analysis, and proposes additional applications for the qualitative analysis of ceramic paints using pXRF.

\section{Key Words}

Portable X-ray fluorescence (pXRF); time of flight-laser ablation-inductively coupled plasmamass spectrometry (TOF-LA-ICP-MS); ceramic paints; White Mountain Red Ware; Ancestral Pueblo

\section{Introduction}

Archaeologists working in the American Southwest have made great strides in the compositional analysis of ceramic paints (Cordell and Habicht-Mauche 2012, Huntley, et al. 2007, Huntley 2006, Fenn et al. 2006, Speakman and Neff 2002, Van Keuren et al. 2013), and much of this work utilizes laser ablation-inductively coupled plasma-mass spectrometry (LA- 
34 ICP-MS) to precisely and accurately measure the chemical composition of paints via tight control of the location and depth of sample locations on the painted surfaces of ceramics (Speakman and Neff 2005, Duwe and Neff 2007). The resulting data have been useful for inferring pigmenting techniques, potter learning networks, and other dimensions of ceramic production in many areas of the world (e.g., Vaughn et al. 2005, Backes et al. 2012, Cecil and Neff 2006).

Despite its utility for inferring ancient paint recipes, LA-ICP-MS has been largely limited to the analysis of sherd samples. Assays require analytical equipment that is non-portable and requires the removal of small fragments for efficient analysis of multiple specimens. As such, it cannot be readily applied to whole vessels curated in museums and other research facilities that respect to inferring the fuller socio-economic context of production since whole vessels provide the clearest picture of decorative variation and overall vessel use. Thus, LA-ICP-MS analysis of sherd samples has limited applicability when archaeologists are interested in linking technological diversity of paints with the stylistic behavior of potters in the past.

In this paper we illustrate how portable X-ray fluorescence (pXRF) can extend sherdbased LA-ICP-MS to the characterization of paints on whole vessels. In an earlier project, Van Keuren and colleagues used LA-ICP-MS to identify the basic paint "recipes" of glaze-painted red ware sherds from fourteenth-century Ancestral Pueblo sites (Van Keuren et al. 2013). In this paper, we use these data as a baseline for examining a large corpus of painted whole vessels using $\mathrm{pXRF}$. Our results illustrate both the use of pXRF for studying the paints in museum whole 
composition in ceramic paints. The study also further clarifies the social contexts of ancient Pueblo pottery during an important period of cultural change.

\section{Research Background}

\section{2a. Archaeological context}

Our study concerns the production of glaze-painted White Mountain Red Ware (hereafter "WMRW") in east-central Arizona during the early Pueblo IV period (AD 1275/1300-1400). Pottery types in this ware sequence were red-slipped and decorated with black and white designs (Fig. 1). Potters experimented with pigments and firing regimes to yield a lustrous (or glazed) effect with black paints by using key minerals as fluxing agents and colorants. Lead was the primary fluxing agent but copper and manganese were also added as both colorants and possible fluxing agents. Beyond these technological innovations, potters also began to apply new types of decorative subject-matter on painted bowls (Crown 1994). Potters at a handful of large Silver Creek villages (Fig. 2) produced a new representational-style pottery type (Fourmile Polychrome or FP) by the 1320s (Carlson 1970). The type is distinguished from earlier Pinedale-style vessels by its presentation of masked figures, macaws, and other iconographic forms on bowl interiors. Regional scholars attribute this ceramic transition along with other archaeological evidence to the emergence of new religious traditions and practices (Crown 1994, Adams 1991, Van Keuren and Glowacki 2011). The vessels may have been produced by specialists working in a handful of Silver Creek villages (Van Keuren et al. 2013), and a recent use-wear analysis demonstrates that they were used less intensively than earlier WMRW types (Van Keuren and Cameron 2015).

In an earlier study, Van Keuren (2006) examined a large corpus of WMRW whole vessels in museums and recognized the presence of "hybrid" Fourmile-style WMRW bowls (Fig. 
1b). These vessels mimic some of the fundamental decorative features of Fourmile Polychrome but lack the iconographic-style layouts of bowl interiors. Painted designs also rarely exhibit the surface luster that is commonly found on glaze-painted WMRW, suggesting technological differences in the manufacturing process. Both stylistic and technological differences thus suggest that "classic" Fourmile Polychrome (Fig. 1a) was produced by individuals with specialized skills, knowledge, or access to production resources that was not available to potters who produced hybrid versions. The chemical composition of paints on both categories of Fourmile-style WMRW is directly germane to this issue.

\section{2b. Previous compositional research}

Employing protocols established by Duwe and Neff (2007), Van Keuren and colleagues (2013) used TOF-LA-ICP-MS (time-of-flight laser ablation-inductively coupled plasma-mass spectrometry) to examine the composition of 463 sherds representing Pinedale-and Fourmilestyle polychromes; the sample included sherds with two decorative features of hybrid WMRW that can be observed on rim sherds. These were recovered primarily from three possible producer villages in the Silver Creek area (Fourmile, Shumway, and Pinedale ruins). Parts per million assays of 60 elements were analyzed with principal components analysis (PCA) to define five compositional groups (Van Keuren et al. 2013:681-683). These groups were primarily defined by relative amounts of lead $(\mathrm{Pb})$, copper $(\mathrm{Cu})$, manganese $(\mathrm{Mn})$, and antimony (Sb). The compositional groups correspond with the "recipes" used by pottery to render different hues in black paints. Based on the lack of luster, it was anticipated that Fourmile-style hybrids would have lower lead content. However, it was found that the paint composition of hybrids fell into all five of the composition groups with the majority in group 2a (high lead and copper, low manganese). The study showed that potters producing the hybrid bowls introduced lead but 
102 failed to render the luster of glaze-painted designs observed on Fourmile Polychrome. The

103 potters who produced hybrids apparently had access to key mineral resources, but were not

104 rendering glaze-painted designs. Van Keuren and colleagues (2013) speculated that these potters

105 were not able to achieve the specialized firing regime required to produce glaze-painted designs,

106 perhaps because they lacked access to needed fuels or the required knowledge of WMRW firing

107 techniques. At least part of this variance may also be due to the heterogeneous nature of these

108 minerals in their raw form; ancient potters likely processed ores that were aggregates of copper,

109 manganese, and galena (Blinman et al. 2012).

110 Although the type-sequence of WMRW was defined many decades ago (Carlson 1970,

111 Colton and Hargrave 1937), large-village ceramic assemblages are notoriously complex in the

112 Southwest (see Smith 1962). The nuances of decoration that identify WMRW hybrids can be

113 discerned on rim sherds but are sometimes impossible to recognize on body sherds making

114 classification of sherds problematic. WMRW hybrids are best identified through the careful

115 observation of whole vessel design layouts as well as specific features on bowl exteriors; once

116 fragmented, a vessel can easily yield sherds that might be assigned to different ceramic types.

117 Whole vessel examples, for instance, combine both Fourmile-style designs with earlier elements.

118 Fortunately, large numbers of fourteenth-century WMRW whole vessels are available for

119 stylistic research since the key archaeological sites were targeted by early researchers. Jesse

120 Walter Fewkes excavated a large whole vessel assemblage from Fourmile Ruin in 1896, which is

121 now curated in the National Museum of Natural History (NMNH). In earlier research, this

122 collection served as a foundation for defining hybrid types among late WMRW assemblages in

123 east-central Arizona (Van Keuren 2001).

\section{3. Methodology}



control the precise location and penetration depth of the laser. Typical analysis requires the removal of small $(\sim 4 \mathrm{~mm} \times \sim 4 \mathrm{~mm})$ pieces of the artifacts to fit into the standard ablation chamber. While there have been some efforts to develop laser ablation chambers capable of sealing to the external surfaces of whole ceramic vessels and thus limiting the sample destruction to nearly invisible ablation marks (Laure Dussubieux, personal communication 2014), the entire system is not portable and the ability to standardize and normalize the data from multiple vessels

132 is difficult. For the non-destructive on-site analysis of museum collections of complete vessels 133 we have developed a method utilizing qualitative $\mathrm{pXRF}$ spectra analysis.

The pXRF is a small handheld instrument that can be taken directly to ceramic collections for analysis. The small size and completely non-destructive nature of the pXRF allow for rapid analyses of interior and exterior paints on whole vessels, and is particularly useful when examining the metallic components of surface paints. While the depth and location of analysis in LA-ICP-MS can be controlled entirely by the regulation of the laser, the location and depth of the pXRF analysis is a function of beam placement and size as well as energy of the resulting

140 fluorescent X-rays. Beam sizes on pXRF instruments are typically about 5mm in diameter (a $1412 \mathrm{~mm} \times 3 \mathrm{~mm}$ oval in the case of the Bruker Tracer used in this study), and can be restricted to 142 individual design elements in most cases. The major limitation to quantitative analysis is the 143 depth of X-ray penetration. The depth of penetration and the ability of resulting fluorescent X144 rays to escape the matrix are largely a function of energy. Low energy X-rays that are most likely 145 to fluoresce elements at the low end of the $0-40 \mathrm{kEv}$ scale are not able to penetrate deep into the 146 sample. In addition, any generated low-energy fluorescence is unable to escape the matrix from 147 greater depths. Thus, the greater an element's peak energy, the greater the depth of matrix 
148 included in the spectra. This is particularly problematic for surface paints as low-energy elements 149 might derive from only the surface paint, while higher energy elements may include x-rays from 150 the underlying slip or paste. The situation is further complicated by the highly variable paint 151 thickness within and between vessels. The qualitative method we have developed to adjust for 152 the quantitative limitations of surface XRF analysis is outlined below. operated at $40 \mathrm{KeV}$ and $15 \mu \mathrm{A}$ using a $\mathrm{Cu}$ (6 mil thick), Ti (12 mil thick), and $\mathrm{Al}$ (2 mil thick) secondary target (filter) to reduce background throughout the lower-energy portion of the 156 spectrum. In all measurements, the instrument window was within $5 \mathrm{~mm}$ of the vessel surface. Distances were minimal for measurements of the convex exteriors and higher in the concave interiors. Comparison of each interior and exterior measurement from each vessel showed no changes (except for those rare cases of clearly different paint recipes) indicating minimal, if any, 160 impact as a result of variations in sample geometry. To control for variable paint thickness and 161 slip and paste compositions, a background spectra was collected from the slip adjacent to the 162 paint. The overlay of the adjacent slip and paint spectra reveal the additional components of the 163 paint. XRF is particularly sensitive to metals, and thus only 10 second analyses were required to 164 visually identify the primary metallic components $(\mathrm{Mn}, \mathrm{Cu}$, and $\mathrm{Pb})$ that are pertinent to the 165 recipes of ancient glaze-painted ceramics. At minimum, two unique paint features were analyzed 166 on both the interior and exterior of the bowls. If additional features of interest were noted, such 167 as color or luster variations, more analyses were conducted. Changes in the observed peaks for 168 manganese, copper, and lead were recorded as no change (1), small peak (2) or large peak (3). 169 The peaks seen in the paint spectra that are not present in the adjacent slip are proportional to the 170 relative concentration of that element as well as the thickness of that area of paint. 
171 4. Results

172 4a. Pilot Study

173 To explore the feasibility of applying the pXRF to identifying compositional groups in 174 whole vessel collections, a blind trial sample of WMRW sherds $(n=25)$ was selected (by 175 VanKeuren) from the larger ICP-MS sample published by Van Keuren and colleagues (2013). 176 Using pXRF, Ferguson was able to predict most of the four primary TOF-LA-ICP-MS 177 compositional groups defined by relative amounts of lead $(\mathrm{Pb})$ and manganese $(\mathrm{Mn})($ Table 1).

178 The technique was less successful at identifying those sherds with low copper (Cu) previously 179 assigned to Group 1, which was not surprising given the loose membership of samples in this 180 group from the earlier LA-ICP-MS analysis. Table 1 illustrates the similar results between the 181 pXRF pilot study and the LA-ICP-MS analysis. The minor differences are likely the result of a 182 difference between the qualitative and nominal data from the pXRF methodology compared to 183 the quantitative and continuous nature of the LA-ICP-MS analysis. Figures 4 and 5 illustrate the 184 association between the compositional groups identified in the LA-ICP-MS analysis and the 185 qualitative groups identified by $\mathrm{pXRF}$.

\section{4b. Whole Vessel Study}

Our primary goal of this research was to build on the pilot study and assess compositional 188 variability in a large corpus of whole WMRW vessels. The ceramic types were previously 189 identified by Van Keuren in a stylistic analysis that relied on the structural organization of design 190 layouts on both bowl interiors and exteriors. Van Keuren and others (2013) relied on these 191 stylistic definitions to categorize sherds for the LA-ICP-MS study, but the study of paint 192 composition had not yet been conducted on a whole vessel sample where distinctions between 193 "classic" and "hybrid" WMRW are recognizable based on decorative layout and execution. In 
194 addition to Fourmile Polychrome and the Fourmile-style hybrids, we included Pinedale-style 195 vessels that were produced prior to the 1320s. Our results are summarized in Table 2 and largely 196 correlate with the patterns identified in the earlier LA-ICP-MS study. Based on the percentages 197 listed in Table 3, the compositional grouping of the pXRF data versus earlier LA-ICP-MS 198 analyses compares favorably. The exception is the larger percentage of Pinedale-style types 199 assigned to groups $3 \mathrm{~b}$ in the earlier analysis, which we suspect this is due to sampling differences 200 between the two studies, or perhaps variance in the ceramic type designations of sherds in the 201 previous analysis. Two additional pXRF groups were also defined in the broader whole vessel 202 analysis. These groups are represented by five vessels that are defined by low $\mathrm{Cu}$ and high $\mathrm{Pb}$ 203 and variable amounts of Mn (Table 2; Fig. 4). Three of these samples may correspond with LA204 ICP-MS Group 1, which included a diverse population of sherds with lower amounts of $\mathrm{Cu}$ and 205 variable $\mathrm{Pb}$ and $\mathrm{Mn}$.

206 The majority of Pinedale-style whole vessels in the NMNH collection fell within two 207 low-Mn pXRF groups D and E that correspond to LA-ICP-MS Groups 2a/2b. Many of the 208 Fourmile Polychrome bowls were squarely assigned to high-Mn pXRF groups B and C (LA209 ICP-MS Groups 3a/3b). The latter vary in relative amounts of $\mathrm{Pb}$, but the temporal trend in 210 increasing introduction of Mn is clear. Van Keuren and colleagues' (2013) suggest that this may 211 be related to conscious efforts on the part of potters to subtly alter the hue of black paints, in 212 some cases, rendering purplish sub-glazes. The Fourmile-style hybrids were produced 213 concurrently with Fourmile Polychrome, but exhibit primarily low-Mn recipes (32 percent versus 21471 percent of FP). One of the primary goals of the study was to assess the relationship between 215 "classic" and "hybrid" Fourmile Polychrome. The vessels that we identified as Fourmile-style 216 hybrids in the NMNH collection were primarily decorated with a low-Mn, high-Pb paint recipe 
217 that corresponds with LA-ICP-MS Group 2a. This group is the predominant "recipe" for earlier

218 Pinedale-style pottery made at these villages, suggesting that the individuals who manufactured

219 Fourmile-style hybrids were drawing on an earlier paint recipe.

WMRW is invariably painted with black designs on red slip (with or without white outlines), but some of the whole vessels exhibited color differences in the paints (Van Keuren et al. 2013). There were occasionally variations in the intensity and color of the darker paints. In fact, multiple paint compositions were found on 12 out of 189 of the vessels analyzed, and these different compositions were obviously different recipes - not minor variations in the same basic mix of minerals. The majority of the paints on the WMRW vessels we examined contained varying concentrations on $\mathrm{Mn}, \mathrm{Cu}$, and $\mathrm{Pb}$. The general lack of Fe-based paints is expected due to the difficulty in getting an oxidized Fe paint to visually stand out from the high-Fe slips used to create the red background colors. The exterior designs on the vessel in Figure 5 reveal an attempt to use $\mathrm{Fe}$ and the more typical $\mathrm{Mn}-\mathrm{Cu}-\mathrm{Pb}$ paints to achieve multiple colors. The vessel displays what may represent a large bear and four deer on the exterior. The bear is painted in a high $\mathrm{Cu}$ and $\mathrm{Pb}$ paint with some white clay accents while the deer is painted in a Fe-based paint with the hooves in black $\mathrm{Cu}-\mathrm{Pb}$ paint and the tail and antlers in white slip. The rendering of $\mathrm{Fe}$ based paints are apparent in some of the deer images as they appear to have mostly oxidized the

234 same color as the slip, leaving only the hooves and tail to indicate the deer form.

\section{Discussion/conclusions}

This preliminary study demonstrates the utility of studying glaze-paint composition on whole vessels with pXRF. Our work shows that pXRF can identify groups that were previously defined on the basis of quantitative data. In the case of WMRW, we were able to recognize specific paint "recipes" on NMNH whole vessels that were defined by the earlier LA-ICP-MS 
analysis of sherds. Although the latter is a far superior approach to defining ancient paint recipes, it cannot feasibly be applied to the analysis of whole vessels. This presents a conundrum since we can only appreciate and document the diversity of decorative motifs and design layouts by analyzing whole vessels (versus sherds). The combination of both qualitative and quantitative methods permitted us to move beyond traditional typologies and investigate how paint composition relates to variation within singular ceramic types. More important, the pXRF analysis corroborated Van Keuren and colleagues' suggestion that iconographic-style pottery involved diverse paint recipes in east-central Arizona. The potters who produced the NMNH whole vessel assemblage were clearly working with different sets of technical knowledge as well as raw materials. Potters regularly used $\mathrm{Cu}$ as a colorant and perhaps a flux along with variable amounts of $\mathrm{Pb}$. In "classic" WMRW vessels (Pinedale-style bowls and Fourmile Polychrome in our sample), the result was lustrous black paints. By the 1320s, Fourmile Polychrome potters additionally introduced $\mathrm{Mn}$ as a colorant. The interiors of hybrid bowls are typically painted with earlier Pinedale-style designs (Van Keuren 2006), and our analysis show that these vessels typically used the same low-Mn recipe that characterizes Pinedale-style types (Table 2). Taken together, these patterns suggest that the makers of hybrid Fourmile-style pottery drew on preexisting bodies of manufacturing knowledge. Surface luster is absent on the black painted designs of these hybrids (as is Mn). The community of potters who produced these vessels may not have acquired the technological expertise of other WMRW-potters at Fourmile Ruin. Van Keuren and colleagues' (2013) suggest that Fourmile Polychrome was produced by potters who controlled access to manufacturing knowledge or raw materials.

The pXRF analysis of whole vessels further revealed a compositional pattern not accounted for in the earlier ICP-MS analysis. WMRW potters were at times using multiple paint 
263 mixtures on single vessels presumably to achieve variable hues. This confirms what

264 archaeologists have long suspected: compositional differences may exist within individual

265 vessels. The use of multiple chemically-distinct paint recipes is most clearly evident in one

266 vessel in which certain elements of the deer and bear on the exterior of the bowl were painted in

267 a typical high $\mathrm{Mn}$ and $\mathrm{Cu}$ paint, while the bodies of the deer were painted in a high Fe paint that

268 faded to varying degrees due to the oxidation firing needed to achieve the red color desired in the

269 high Fe slip. There is great potential to explore the variability of paint composition within single

270 vessels, which is typically impossible with small sherds.

271 This study establishes a protocol for extending LA-ICP-MS studies of sherds to non-

272 destructive $\mathrm{pXRF}$ analyses of both whole vessel collections, and perhaps more equally important,

273 rapid field analyses at archaeological sites where sherds cannot be collected for off-site

274 compositional analyses. The latter provides the additional opportunity to radically increase our

275 sample sizes in research on ancient pottery paint recipes. With further refinement, we anticipate

276 that pXRF can be used to non-destructively and expediently analyze both sherds in field settings

277 and whole vessels in museum collections (including those subject to imminent repatriation).

278

279 Acknowledgements

280 The LA-ICP-MS data published by Van Keuren and colleagues (2013) and used in this

281 paper was collected through the support of grants from the National Science Foundation (BCS

282 0753156, 0808852, \& 0917702). Research in support of this paper was supported in part by a

283 NSF grant (BCS 1110793) to the MURR Archaeometry Laboratory. We thank James Krakker

284 and other staff members at the NMNH's Museum Support Center for facilitating access to the

285 collections and assisting with our research. 
286

287

288 


\section{References}

291 Adams, E.C., 1991. The Origin and Development of the Pueblo Katsina Cult, University of 292 Arizona Press, Tucson.

293 Backes, C.J., Jr., Cheetham, D., Neff, H., 2012. The Color of Influence: A Provenance Study of 294 Hematite-Based Paints on Early Olmec Carved Pottery. Latin American Antiquity 23, 70-92.

295 Blinman, E., Schleher, K.L., Dickerson, T., Herhahn, C.L., Gundiler, I., 2012. Making a Glaze:

296 Multiple Approaches to Understanding Rio Grande Glaze Paint Technology, In: Cordell, L.S., 297 Habicht-Mauche, J.A. (Eds.), Potters and Communities of Practice: Glaze Paint and Polychrome 298 Pottery in the American Southwest, A.D. 1250 to 1700. The University of Arizona Press, 299 Tucson, pp. 107-116.

300 Carlson, R.L., 1970. White Mountain Redware: A Pottery Tradition of East-Central Arizona and 301 Western New Mexico, University of Arizona Press, Tucson.

302 Cecil, L.G., Neff, H., 2006. Postclassic Maya slips and paints and their relationship to socio303 political groups in El Peten, Guatemala Journal of Archaeological Science 33, 1482-1491.

304 Colton, H.S., Hargrave, L.L., 1937. Handbook of Northern Arizona Pottery Wares, Museum of 305 Northern Arizona, Flagstaff, Arizona.

306 Cordell, L.S., Habicht-Mauche, J.A., 2012. Potters and Communities of Practice: Glaze Paint 307 and Polychrome Pottery in the American Southwest, A.D. 1250 to 1700, Anthropological Papers 308 of the University of Arizona 75, The University of Arizona Press, Tucson.

309 Crown, P.L., 1994. Ceramics and Ideology: Salado Polychrome Pottery, University of New 310 Mexico Press, Albuquerque. 
311 Duwe, S., Neff, H., 2007. Glaze and Slip Pigment Analyses of Pueblo IV period Ceramics from

312 East-central Arizona Using Time of Flight-Laser Ablation-Inductively Coupled Plasma-Mass

313 Spectrometry (TOF-LA-ICP-MS). Journal of Archaeological Science 34, 403-414.

314 Fenn, T.R., Mills, B.J., Hopkins, M., 2006. The Social Contexts of Glaze Paint Ceramic

315 Production and Consumption in the Silver Creek Area. In: Habicht-Mauche, J.A., Huntley, D.L.,

316 Eckert, S.L. (Eds.), The Social Life of Pots: Glaze Wares and Cultural Dynamics in the

317 Southwest, AD 1250-1680. The University of Arizona Press, Tucson, pp. 60-85.

318 Huntley, D.L., 2006. From Recipe to Identity: Exploring Zuni Glaze Ware Communities of 319 Practice. In: Habicht-Mauche, J.A., Huntley, D.L., Eckert, S.L. (Eds.), The Social Life of Pots: 320 Glaze Wares and Cultural Dynamics in the Southwest, AD 1250-1680. The University of 321 Arizona Press, Tucson, pp. 105-123.

322 Huntley, D.L., Spielmann, K.A., Habicht-Mauche, J.A., Herhahn, C.L., Flegal, A.R., 2007. Local 323 Recipes or Distant Commodities? Lead Isotope and Chemical Compositional Analysis of Glaze 324 Paints from the Salinas Pueblos, New Mexico. Journal of Archaeological Science 34, 1135-1147. 325 Smith, W., 1962. Schools, Pots, and Potters. American Anthropologist 64, 1165-1178.

326 Speakman, R.J., Neff, H., 2002. Evaluation of Painted Pottery from the Mesa Verde Region 327 Using Laser Ablation-Inductively Coupled Plasma-Mass Spectrometry (LA-ICP-MS). American 328 Antiquity 67, 137-144.

329 Speakman, R.J., Neff, H., 2005. The Application of Laser Ablation-ICP-MS to the Study of 330 Archaeological Materials--An Introduction. In: Speakman, R.J., Neff, H. (Eds.), Laser Ablation331 ICP-MS in Archaeological Research. University of New Mexico Press, Albuquerque, pp. 1-14. 
332 Van Keuren, S., 2001. Ceramic Style and Reorganization of Fourteenth Century Pueblo

333 Communities in East-Central Arizona, Department of Anthropology, University of Arizona, 334 Tucson.

335 Van Keuren, S., 2006. Decorating Glaze-Painted Pottery in East-central Arizona. In: Habicht336 Mauche, J.A., Huntley, D.L., Eckert, S.L. (Eds.), The Social Life of Pots: Glaze Wares and 337 Cultural Dynamics in the Southwest, AD 1250-1680. The University of Arizona Press, Tucson, $338 \quad$ pp. $86-104$.

339 Van Keuren, S., Cameron, G.E., 2015. The Lives of Painted Bowls at Ancestral Pueblos in East340 central Arizona, American Antiquity 80, 25-45.

341 Van Keuren, S., Glowacki, D.M., 2011. Studying Ancestral Pueblo Religion. In: Glowacki, 342 D.M., Van Keuren, S. (Eds.), Religious Transformation in the Late Pre-Hispanic Pueblo World. 343 University of Arizona Press, Tucson, pp. 1-22.

344 Van Keuren, S., Neff, H., Agostini, M.R., 2013. Glaze-paints, Technological Knowledge, and 345 Ceramic Specialization in the Fourteenth-century Pueblo Southwest. Journal of Anthropological 346 Archaeology 32, 675-690.

347 Vaughn, K.J., Conlee, C.A., Neff, H., Schreiber, K.J., 2005. A Compositional Analysis of Nasca 348 Pigments: Implications for Craft Production on the Pre-Hispanic South Coast of Peru. In: 349 Speakman, R.J., Neff, H. (Eds.), Laser Ablation-ICP-MS in Archaeological Research. University 350 of New Mexico Press, Albuquerque, pp. 139-153. 


\section{Table Captions}

Table 1. Comparison of ICP-MS and pXRF groups in pilot study ( $\mathrm{n}=20$ samples).

Table 2. Elemental proportions of pXRF groups and counts of compositional groups by ceramic type.

Table 3. Row percentages of compositional groups by ceramic type for $\mathrm{pXRF}$ and ICP-MS (parentheses) analyses.

\section{Figure Captions}

Figure 1. White Mountain Red Ware (WMRW) bowl interiors. Examples of both "classic" (1a) and "hybrid" (1b) Fourmile Polychrome.

Figure 2. The Silver Creek area, east-central Arizona.

Figure 3. (Right) Bivariate plot of copper and lead showing the separation of ICP Group 1. The spectra on the left are examples from the three pXRF groups $(\mathrm{A}, \mathrm{F}$, and $\mathrm{G})$ that match with ICP Group 1.

Figure 4. (Center) Bivariate plot of manganese and lead showing the separation of ICP Groups $2 \mathrm{a}, 2 \mathrm{~b}, 3 \mathrm{a}$, and $3 \mathrm{~b}$. The four spectra match the corresponding $\mathrm{pXRF}$ and ICP groups.

Figure 5. Detail of bowl exterior design with Fe-based paints. The bear on the left is painted with a high copper and lead paint while the multiple deer bodies are painted with a high iron paint. The deer on the right was likely exposed to higher oxygen levels during the firing and the paint on the body oxidized to the same color as the slip. The hooves were painted with the same mineral paint as the body of the bear. 
Table 1. Comparison of ICP-MS and pXRF groups in pilot study ( $\mathrm{n}=20$ samples).

\begin{tabular}{|c|c|c|c|c|c|}
\hline \multicolumn{6}{|c|}{ pXRF Groups } \\
\hline $\begin{array}{l}\text { ICP-MS } \\
\text { Groups }\end{array}$ & A & B & $\mathrm{C}$ & $\mathrm{D}$ & $\mathrm{E}$ \\
\hline 1 & 2 & 1 & 1 & 1 & - \\
\hline $2 \mathrm{a}$ & - & - & - & 5 & - \\
\hline $2 b$ & - & - & 1 & 1 & 3 \\
\hline $3 a$ & - & 4 & - & 1 & - \\
\hline $3 b$ & 1 & 1 & 3 & - & - \\
\hline
\end{tabular}


Table 2. Elemental proportions of pXRF groups and counts of compositional groups by ceramic type.

\begin{tabular}{rcccccccc}
\hline ICP-MS Groups & $1 ?$ & $3 \mathrm{a}$ & $3 \mathrm{~b}$ & $2 \mathrm{a}$ & $2 \mathrm{~b}$ & $1 ?$ & 1 & \\
pXRF Groups & $\mathbf{A}$ & $\mathbf{B}$ & $\mathbf{C}$ & $\mathbf{D}$ & $\mathbf{E}$ & $\mathbf{F}$ & $\mathbf{G}$ & \\
\hline $\mathrm{Mn}$ & + & + & + & - & - & + & - & \\
$\mathrm{Pb}$ & - & + & - & + & - & + & + & \\
$\mathrm{Cu}$ & - & + & + & + & + & - & - & $\mathrm{n}$ \\
\hline Pinedale-style types $^{\mathrm{a}}$ & - & 14 & 6 & $\underline{39}$ & 3 & - & - & 62 \\
Fourmile Polychrome & 1 & 27 & $\underline{45}$ & 17 & 6 & 4 & 1 & 101 \\
Fourmile-style hybrids & 0 & 4 & 3 & $\underline{17}$ & 4 & - & - & 28 \\
\hline
\end{tabular}

${ }^{\mathrm{a}}$ Include Pinedale Black-on-red/Polychrome and Cedar Creek Polychrome 
Table 3. Row percentages of compositional groups by ceramic type for $\mathrm{pXRF}$ and ICP-MS (parentheses) analyses.

TOF-LA-ICP-MS / pXRF groups

\begin{tabular}{rcccccc} 
& $1 / \mathrm{G}$ & 2A / D & 2B / E & 3A / B & 3B / C & $\mathrm{n}$ \\
\hline \multirow{2}{*}{ Pinedale-style types $^{\mathrm{a}}$} & - & $\underline{62.9}$ & 4.8 & 22.6 & 9.7 & 62 \\
& $(1.0)$ & $(48.5)$ & $(4.1)$ & $(15.1)$ & $(31.3)$ & $(99)$ \\
\cline { 2 - 7 } Fourmile Polychrome & 4.2 & 17.8 & 6.3 & 28.1 & $\underline{46.9}$ & 95 \\
& $(7.1)$ & $(24.6)$ & $(5.2)$ & $(26.6)$ & $(36.5)$ & $(252)$ \\
\cline { 2 - 7 } Fourmile-style hybrids & - & $\underline{60.7}$ & 14.3 & 14.3 & 10.7 & 28 \\
& $(10.6)$ & $(50.0)$ & $(1.9)$ & $(25.0)$ & $(12.5)$ & $(104)$ \\
\hline
\end{tabular}


Figure 1a and 1b. White Mountain Red Ware (WMRW) bowl interiors. Examples of both "classic" (1a) and "hybrid" (1b) Fourmile Polychrome.

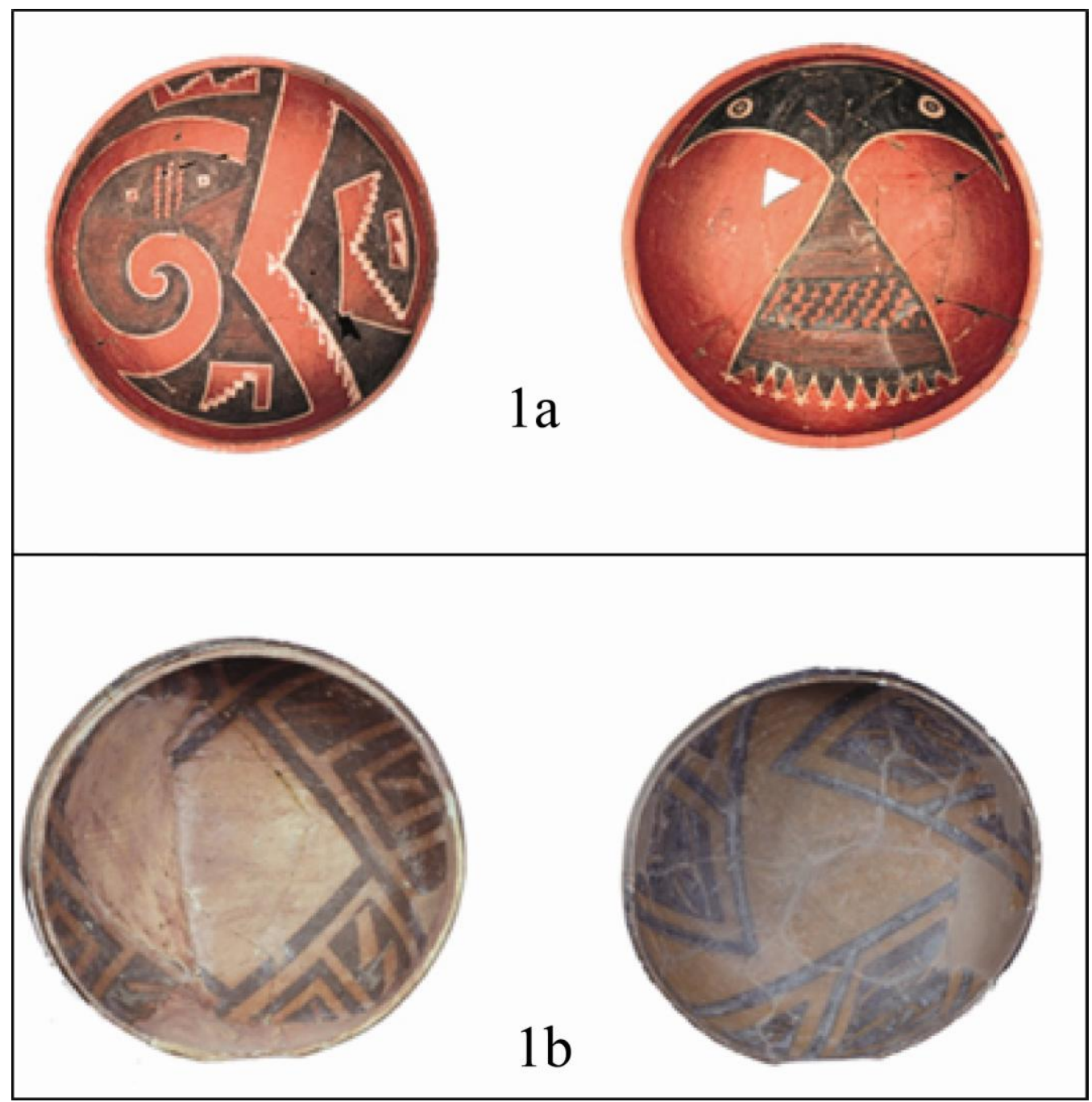


Figure 2. The Silver Creek area, east-central Arizona.

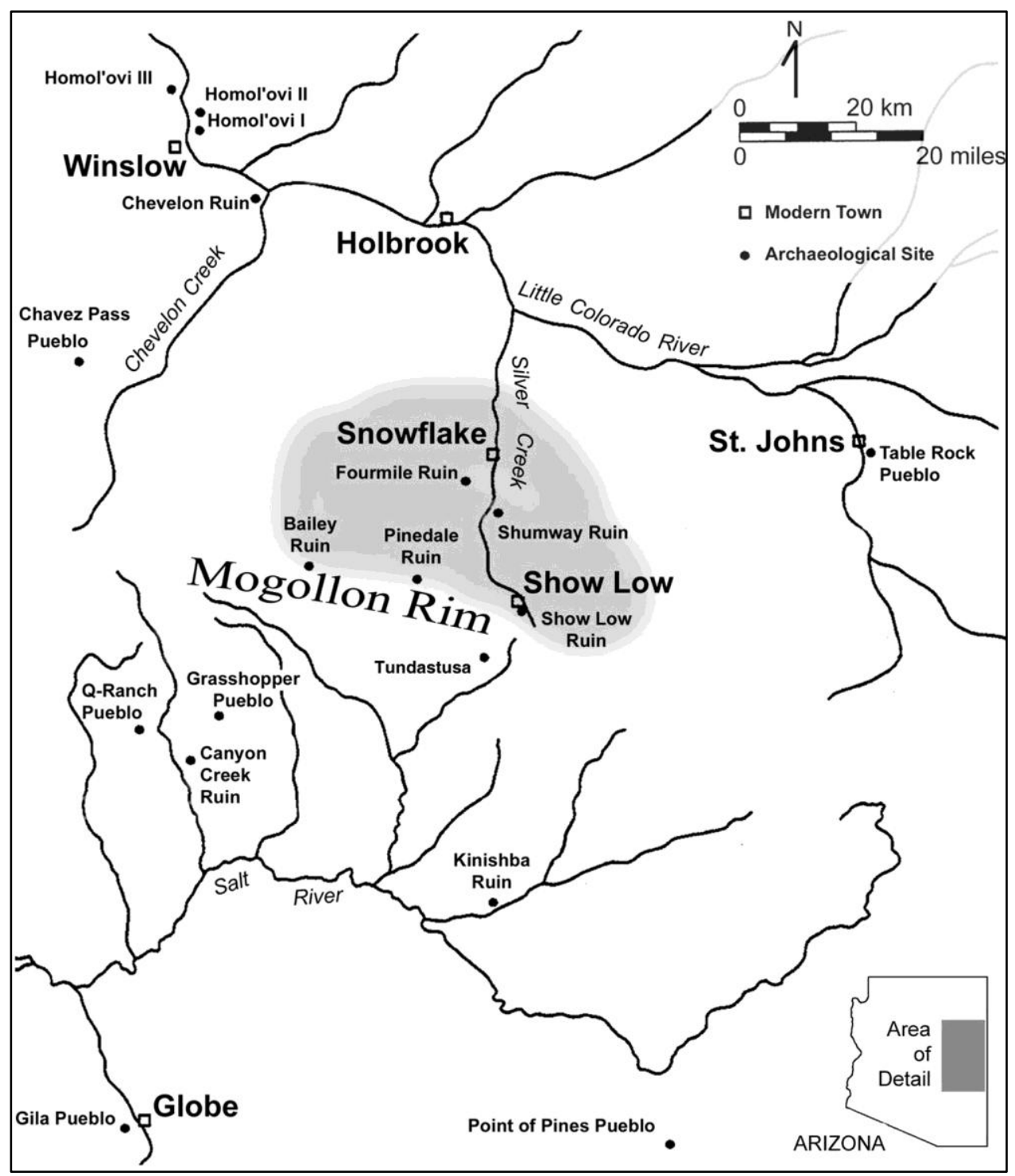


Figure 3. (Right) Bivariate plot of copper and lead showing the separation of ICP Group 1. The spectra on the left are examples from the three pXRF groups (A, F, and G) that match with ICP Group 1.

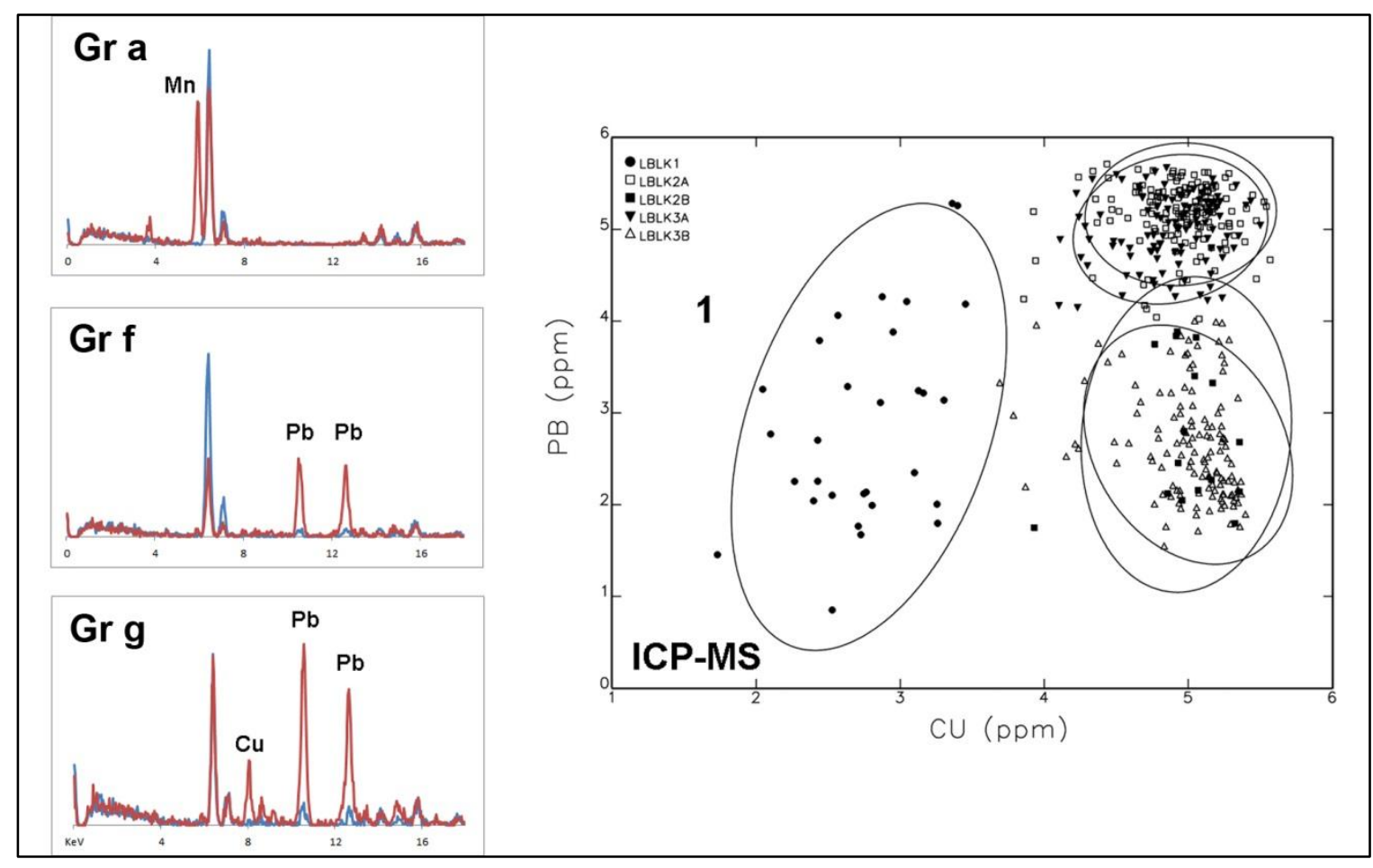


Figure 4. (Center) Bivariate plot of manganese and lead showing the separation of ICP Groups $2 \mathrm{a}, 2 \mathrm{~b}, 3 \mathrm{a}$, and $3 \mathrm{~b}$. The four spectra match the corresponding $\mathrm{pXRF}$ and ICP groups.

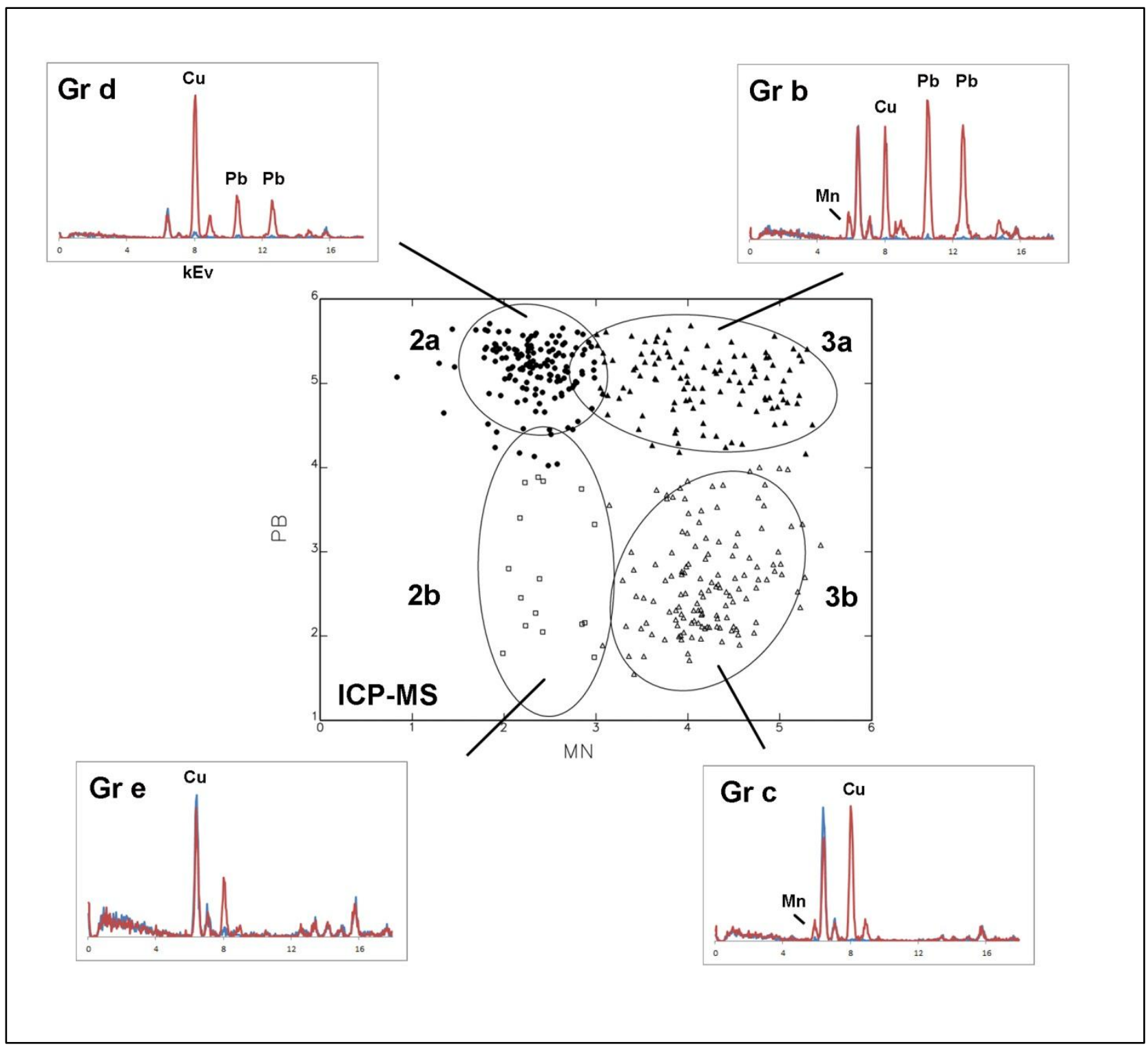


Fig. 6. Detail of bowl exterior design with Fe-based paints. The bear on the left is painted with a high copper and lead paint while the multiple deer bodies are painted with a high iron paint. The deer on the right was likely exposed to higher oxygen levels than the deer in the center during the firing and the paint on the body oxidized to the same color as the slip. The hooves were painted with the same mineral paint as the body of the bear.

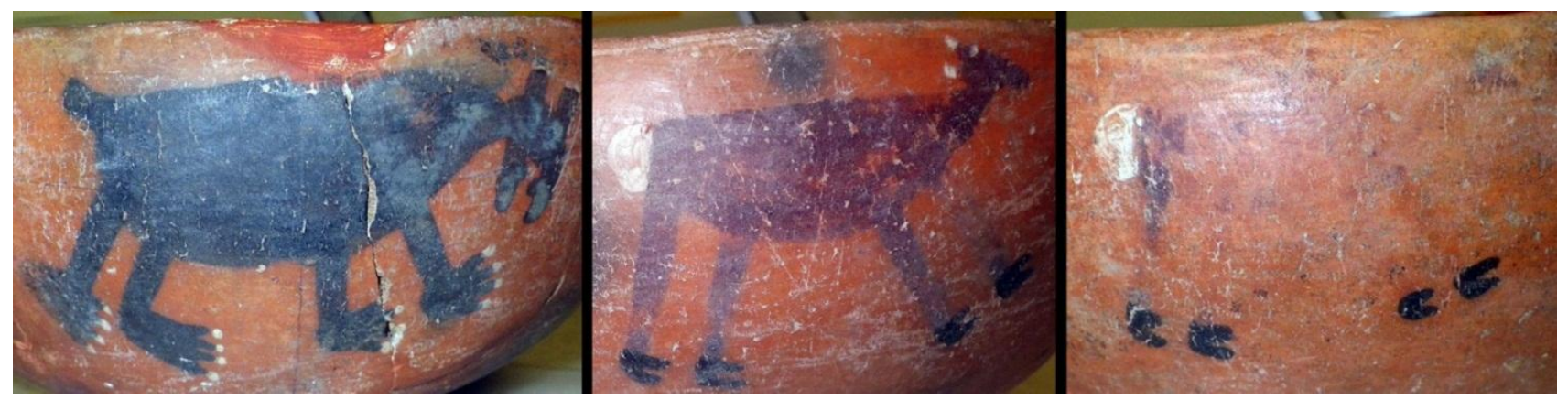

